\title{
Study of Negative Ion Formations by Electron Impact $I$. Negative Ions Produced from Acrylonitrile
}

\author{
Toshio Sugiura*, Kazuo Arakawa* and Akira Matsumoto**
}

(Received August 2, 1966)

\begin{abstract}
Utilizing a conventional electron gun and mass spectrometer, the formation of negative ions at wide electron energies ( 0 to $100 \mathrm{ev}$ ) have been investigated for an acrylonitrile. The ionization efficiency curves have been obtained for the negative ions including $\mathrm{C}^{-}, \mathrm{CH}^{-}, \mathrm{C}_{2}^{-}, \mathrm{C}_{2} \mathrm{H}^{-}, \mathrm{CN}^{-}$, $\mathrm{HCN}^{-}, \mathrm{C}_{3}{ }^{-}, \mathrm{CCN}^{-}, \mathrm{CHCN}^{-}, \mathrm{C}_{2} \mathrm{CN}^{-}, \mathrm{C}_{2} \mathrm{HCN}^{-}$and $\mathrm{C}_{2} \mathrm{H}_{2} \mathrm{CN}^{-}$. The appearance potentials of these negative ions have been determined for both processes of the dissociative resonance capture and ion-pair production, and some of the ions have two or more appearance potentials in each processes. The $\mathrm{O}^{-}$ions produced from $\mathrm{O}_{2}$ and $\mathrm{CO}$ were used for an energy calibration in establishing the appearance potentials, and $\mathrm{SF}_{6}{ }^{-}$ions from $\mathrm{SF}_{6}$ were also used on energy calibration for the electron energy near zero ev. The pressure effects of the formation of these negative ions have been studied in various electron energies over the whole pressure ranges (presumably from $10^{-4}$ to $10^{-7} \mathrm{mmHg}$ in the ionization chamber). From the studies of the pressure effects for the negative ion formation, it has been observed that the intensities of the negative ions produced by the processes of all dissociative resonance capture were increased lineary for pressure increased, but on the other hand the processes of the ion-pair production indicated more complicated dependency, that the dependencies of the ion intensity on the pressure have various mode among the ions from 1st to 4th order against the pressure. Possible explanations of the formation mechanisms of the negative ions are discussed.
\end{abstract}

\section{Introduction}

The informations of the negative ions have been very important for a number of fields, for example the analysis of the compounds include the stable isotopes, the electro-chemistry and the chemistry in the high space. Recently, the studies under the interest of the structural and stereochemical problems have been published on the negative ions produced by electron impact. ${ }^{1-3}$ But there are not so many detailed investigations except for the halogen or the sulphur compounds, ${ }^{4-6}$ for the reason of that the relative intensity of the most negative ions detected by mass spectrometer is generally very lower than that of the positive ions. Moreover, many of the negative ions are formed by the complex mechanisms, and also some of the negative ions have the relatively shorter life time compared with that of the positive ions.

In the field of the radiation chemistry, the mass spectra of the positive ions have been widely applied to the explanation and prediction of the mechanisms for the initial reaction in the interaction of ionizing radiation to matter. There are valuable sources of informations on primary positive ions resulting from electron impact by mass spectrometry. On the other hand the negative ions have been considered to be important active intermediates in radiation-induced polymerizations and other reactions. There are, however, no corresponding informations on negative ions available in the literature, except for some of the investigations of the ion molecule reaction for the negative ions $^{7-9}$. Because of the disparity, the role of negative ions in the field of radiation chemistry has seldom been considered substantially. It is of great importance to study of the primary processes

* Japan Atomic Energy Research Institute, Takasaki Radiation Research Establishment (Watanuki-machi, Takasaki, Gumma-ken)

** Department of Chemistry, College of General Education, University of Osaka Prefecture (4-chome, Mozu-Umemachi, Sakai,Osaka) 
in the radiation-induced chemical reaction in order to elucidate the active species, and the investigation of the negative ions by the mass spectrometry is quite useful means for this purpose like as the studies of the positive ions. The mass spectrometric measurements can provide the information concerning the negative ions of the molecules or radicals produced by electron impact in the ionization chamber. The present investigation was carried out to measure and identify the negative ions of acrylonitrile formed as a result of electron impact by means of mass spectrometer. Ionization efficiency curves and appearance potentials of all detected fragment negative ions and the pressure effects of the negative ions produced by various electron energy have been measured. By these studies, it was attempted to find a clue for understanding the initiation mechanism of the radiation-induced anion polymerization of acrylonitrile.

\section{Experimental}

\section{2-1. Mass Spectrometer}

The present results were obtained by using $90^{\circ}$ single focussing Hitachi RMU-6 mass spectrometer that was modified for measurement of the negative ions. The radius of curvature of the ion path and the maximum resolution in mass units of this instrument are $200 \mathrm{~mm}$ and about 850 , respectively. The circuit diagram of the ion accelerating voltage supply practicable easily reverse the polarity shown in Fig. 1. The polarity of the ion accelerating voltage and the ion repeller voltage

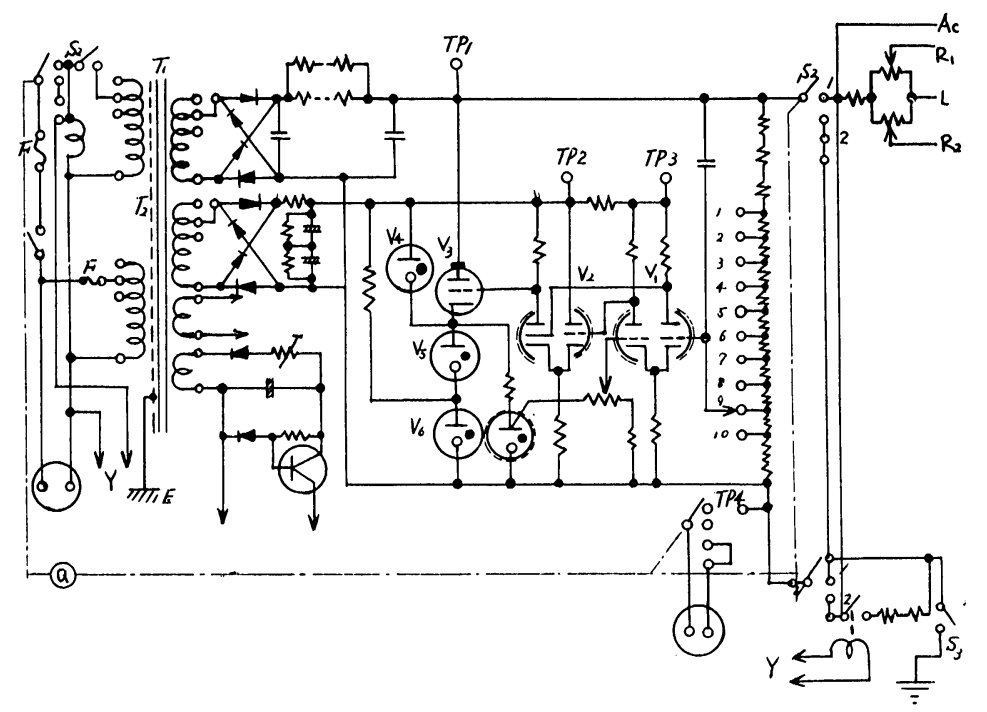

Fig. 1. Circuit diagram of the ion accelerating voltage supply, Ac and $L$ are the source of the ion accelerating voltage and the lens voltage, respectively. $R_{1}$ and $R_{2}$ are the voltage of the separated ion repeller.

are able to easily reversed by means of the switch $S_{2}$ in Fig. 1., independently of the voltage arrangement of the electron gun assembly. An electron gun used is conventional type without any attention to electron energy spread, as the retarding potential difference method. A part of the circuit diagram of the electron acceleration and emission regulation that was modified to obtain the electron energy from 0 to $100 \mathrm{ev}$, shown in Fig. 2. In Fig. 2., T, Ch and B are the electron target, ionization chamber and the electron repeller voltage supply, respectively. Ionizing voltage is variable in the three voltage ranges, which are (1) $50-100 \mathrm{~V}$, (2) $10-50 \mathrm{~V}$ and (3) $0-10 \mathrm{~V}$. In each voltage range, the ionization voltage is able to be varied by means of the variable resister $R V_{1}, R V_{2}$ and $R V_{5}$, respectively. 


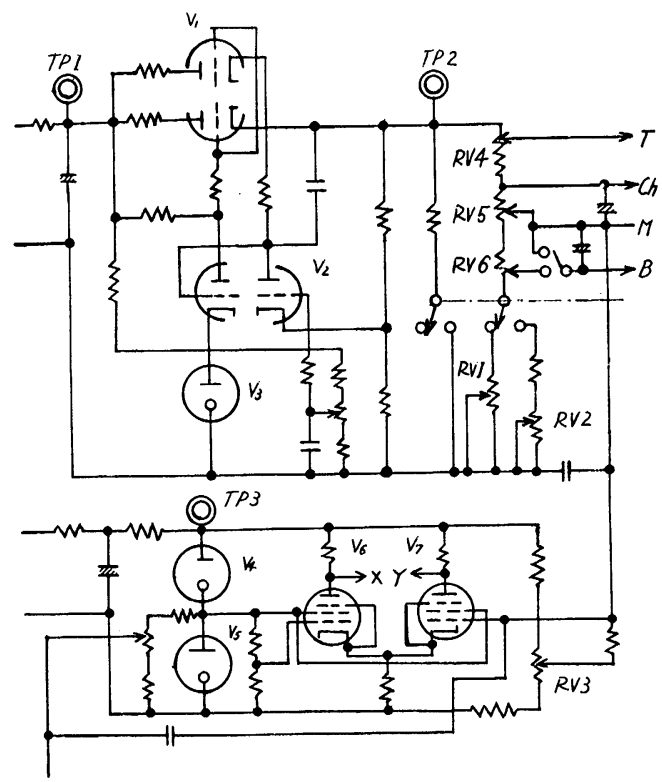

Fig. 2. A part of the circuit diagram of the ionizing voltage supply and the emission regulation, $\mathrm{T}, \mathrm{Ch}$ and $\mathrm{B}$ are the electron target voltage, the voltage of ionization chamber and the voltage of the electron reppeller, respectively.

The variable resister $\mathrm{VR}_{3}$ is used in order to change the electron currents of the total emission. A vibrating reed electrometer (Hitachi AU-12) was used as the d.c. amplifier, and the out-put currents were recorded by three pen recorder (Rikadenki B-34), and detectable minimum ion currents were $6 \times 10^{-16} \mathrm{~A} / \mathrm{mm}$. During the experiment, the electron currents of the total emission and ion accelerating voltage are maintained constant $100 \mu \mathrm{A}$ and $3.5 \mathrm{kV}$, respectively.

\section{2-2. Calibration of Electron Energy}

For the calibration of the energy of the impact electrons, the $\mathrm{O}^{-}$ions produced from oxygen and carbon monoxide were used, and $\mathrm{SF}_{6}{ }^{-}$ions formed from sulphurhexafluoride were also used for the ionizing voltage at nearly zero ev. The appearance potential have been determined by the linear extrapolation method, as the approximation for the rather widely energy distribution of the impacted electrons.

Observed threshold energy of the certain ions of the acrylonitrile is not always reproducible according to the condition of the ionization chamber. Generally, ionization efficiency curves of the acrylonitrile ions gradually replace to higher energy side, during the repeated measurement using the ionization chamber sufficiently baked out. Consequently, the measurement continued to the oxygen, the ionization efficiency curve of the $\mathrm{O}^{-}$ions replace to low energy side during the continued measurements. The phenomena mentioned above might be caused by the fact that the adsorption layers of the acrylonitrile vapour formed upon the surface of the ionization chamber, and the layer may retard the impact electrons. That is to say these adsorption layers may produce more negatively contact potential on the surface, and these adsorption layers easily reduced by flowing another gas such as oxygen. For that reason, the calibration of the appearance potentials was carried out by the following way. The ionization efficiency curves have been measured on the mixed gases which the acrylonitrile have mixed to the calibration gas as much as same intensity in the measured ions, and the appearance potentials have been determined then the ionization efficiency curves of both ions kept 
the constant position in the successively alternate measurements. The standard value of the appearance potential have been used $4.53 \mathrm{ev}$ for the $\mathrm{O}^{-}$ions measured by Frost and McDowell ${ }^{10}$ using the
R.P.D. method.

\section{2-3. Measurement of Pressure Dependency of Ion Formation}

The pressure dependency of the negative ion formations have been measured by the following method. When the gas in the constant volume is flowed through the gas leak in the appreciable condition, the decrease rate has the following relation:

$$
-\mathrm{dP} / \mathrm{dt}=\alpha \mathrm{P} \text { or } \ln \left(\mathrm{P} / \mathrm{P}_{0}\right)=-\alpha \mathrm{t}
$$

where $P, P_{0}$ and $t$ are pressure, initial pressure and time duration, respectively. If the ion currents is proportional to the pressure, then the relation above is:

$$
\ln \left(\mathrm{I} / \mathrm{I}_{0}\right)=-\alpha^{\prime} \mathrm{t}
$$

where $\mathrm{I}$ and $\mathrm{I}_{0}$ are ion currents and ion currents at $\mathrm{t}=\mathrm{O}$. The constant $\alpha$ is inversely proportional to the square root of the mass of the flowing gas. If the sample reservoir of the mass spectrometer is separated to the small volume (of a few cc.) by a stop cock, while an ion peak is recorded at the constant magnetic field, then the ion currents rapidly decrease exponentially with time. The exponential curve is recorded on the recording paper while the time duration in each $10 \mathrm{sec}$ is marked by time marker. By replotting the obtained exponential curve to semilogarithm (log I vs. time) the straight line is obtained, and the relative value of $a$ is possible to determine from the slope of this line. This relation have been tested by the positive ion currents of several gases having different mass, that is sulphurhexafluoride, acrylonitrile, oxygen and carbon monoxide, the relation described above has been confirmed to be applicable in wide pressure range (presumably from $10^{-4}$ to $10^{-7} \mathrm{mmHg}$ in ionization chamber). By using this relation and method, if a ions are produced in proportional to $n$th power for pressure, then $\mathrm{n}$ is able to be determined by the comparison of $a$ to that obtained from the positive ions.

\section{2-4. Materials.}

Acrylonitrile and acrylonitrile-2- $\mathrm{d}_{1}$ were obtained from Tokyo Kasei Kogyo research grade and Merck Sharp and Dohme of Canada Limited, respectively. These samples were purified by shaking with sodium carbonate unhydrate in vacuum, and after this treatment these were distilled three times in vacuum system. Impurities up to $0.01 \%$ in these samples have not been observed by mass spectrometer. The acrylonitrile-2- $\mathrm{d}_{1}$ concentration was measured by mass spectrometrically using the metastable ion intensities of $\mathrm{M} / \mathrm{e}=12.5\left(\mathrm{CH}_{2} \mathrm{CDCN}^{+} \rightarrow \mathrm{CN}^{+}\right), \mathrm{M} / \mathrm{e}=13.5\left(\mathrm{CH}_{2} \mathrm{CDCN}^{+} \rightarrow \mathrm{CHCD}^{+}\right)$ and $\mathrm{M} / \mathrm{e}=12.75\left(\mathrm{CH}_{2} \mathrm{CHCN}^{+} \rightarrow \mathrm{CN}^{+}\right.$and $\left.\mathrm{CHCH}^{+}\right)$, the determined concentration of the acrylonitrile$2-\mathrm{d}_{1}$ by these analysis was up to $98 \%$. Oxygen and carbon monoxide of the standard cylindrical samples of Takachiho Chemical Industry were used without further purification. Sulphurhexafluoride of tank compressed gas purchased from the Allied Chemical Co. was used after the purification by the three times vacuum distillation. The purities of these gases were also determined by the mass spectrometer, the purity of these gases were better than $99.9 \%$.

\section{Results}

\section{3-1. Identification of Negative Ions}

The mass spectra of the negative ions produced from acrylonitrile by the electron impact are shown in Fig. 3. In Fig. 3, (a) and (b) are obtained by the ionizing electron of $6 \mathrm{ev}$ and $100 \mathrm{ev}$, respectively. As seen in Fig. 3 , the negative ions produced from acrylonitrile were observed in that of $\mathrm{M} / \mathrm{e}=24,25,26,27,28,36,37,38,40,50,51$ and 52 . The other mass peaks seen in Fig. 3 were 


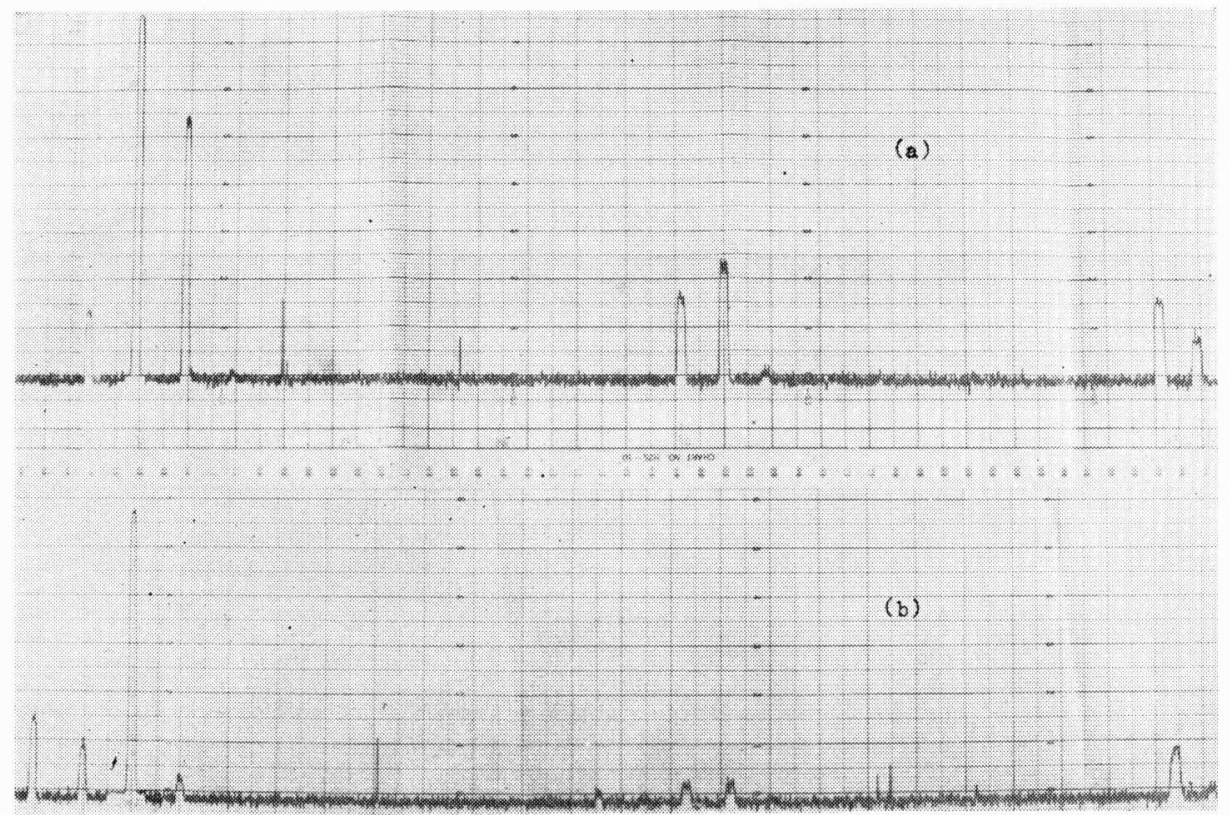

Fig. 3. Negative ion mass spectra of the acrylonitrile, (a) and (b) have been obtained by electron energy of $6 \mathrm{ev}$ and $100 \mathrm{ev}$, respectively.

$\mathrm{M} / \mathrm{e}=12$ and 13. The observed peaks in $\mathrm{M} / \mathrm{e}=28$ and 40 in Fig. 3(a) and $\mathrm{M} / \mathrm{e}=27$ in Fig. 3(b) are the ions contained ${ }^{13} \mathrm{C}$ stable isotopes. In order to identify each mass peaks, the mass spectra of the acrylonitrile-2- $d_{1}$ has been also measured. It was shown in Fig. 4(a) with comparison that of the acrylonitrile- $d_{0}$ in Fig. 4(b). As seen in Fig. 4(a), the mass peaks of $M / e=28,40$ and 53 were newly appeared, and on the other hand the mass peaks of $\mathrm{M} / \mathrm{e}=39$ and 51 are reduced. From these results, each mass peaks are able to be identified as following. In the mass peak of $\mathrm{M} / \mathrm{e}=26$ $\mathrm{C}_{2} \mathrm{H}_{2}{ }^{-}$ions are not included, that consist of only $\mathrm{CN}^{-}$ions. The mass peak of $\mathrm{M} / \mathrm{e}=27$ consists of the rearrangement negative ions of $\mathrm{HCN}^{-}$which contain either $\alpha$ or $\beta$ hydrogen atoms. The mass peak of $\mathrm{M} / \mathrm{e}=51$ is $\mathrm{CCHCN}^{-}$ions. Exception of the rearrangement ions of $\mathrm{HCN}^{-}$, the fragment ions of $\mathrm{M} / \mathrm{e}=39$ and 51 have obviously contained only $\alpha$ hydrogen atoms, and have never been remained $\beta$ hydrogen atoms. The mass peaks of the $\mathrm{C}_{1}$ group were not difference between both mass spectra of the $d_{1}$ and $d_{0}$ compounds. There is no $M / e=14$ peak in the mass spectra of the $d_{1}$ compound, it has shown that the $\mathrm{CH}^{-}$ions are not formed containing the $\alpha$ hydrogen atoms.

\section{3-2. Ionization Efficiency curves and Appearance Potentials}

The ionization efficiency curves of the $\mathrm{O}^{-}$ions formed from oxygen and carbonmonoxide were shown in Fig. 5. In Fig. 5, the electron energy scale have been corrected at the threshold value that is determined by the ionization efficiency curve which is the dissociative resonance capture of the $\mathrm{O}^{-}$ions from oxygen. A standard value of the appearance potential of $\mathrm{O}^{-}$ions from oxygen that are formed by the dissociative resonance capture process, was used $4.53 \mathrm{ev}$ observed by Frost and McDowell ${ }^{10}$.

In Figs. 6, 7 and 8, the typical results of the ionization efficiency curves of the acrylonitrile- $\mathrm{d}_{0}$ were shown. In Fig. 6, the ionization efficiency curves of $\mathrm{C}_{2}^{-}, \mathrm{C}_{2} \mathrm{H}^{-}, \mathrm{CN}^{-}$and $\mathrm{HCN}^{-}$ions were shown. In Fig. 7, the ionization efficiency curves of $\mathrm{C}^{-}, \mathrm{CH}^{-}, \mathrm{C}_{3}^{-}, \mathrm{CCN}^{-}$and $\mathrm{CHCN}^{-}$ions were shown. In Fig. 8, the ionization efficiency curves of $\mathrm{C}_{2} \mathrm{CN}^{-}, \mathrm{CCHCN}^{-}$and $\mathrm{CHCHCN}^{-}$ions were 


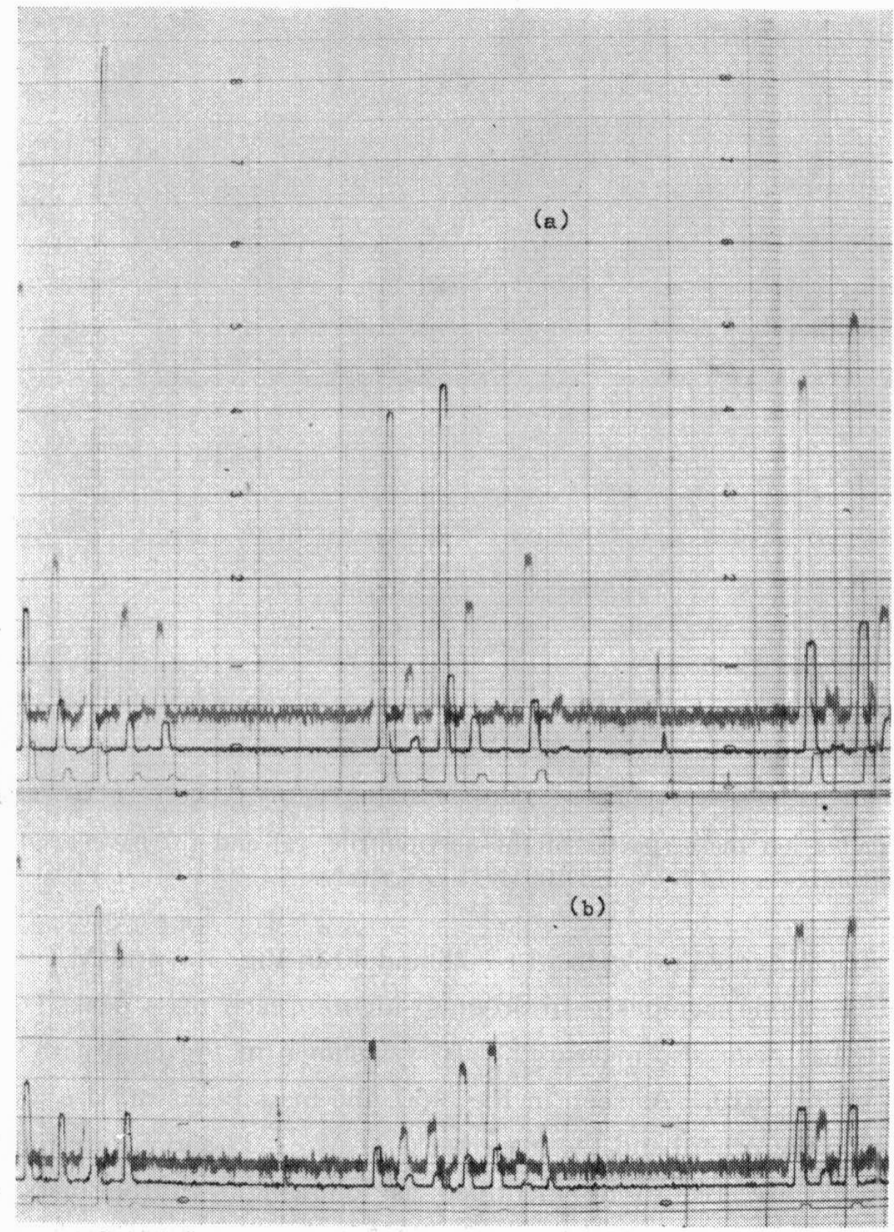

Fig. 4. Comparison of mass spectra of acrylonitrile-2-d (a) and 'acrylonitrile (b), each spectra obtaned by 100 ev electrons.

shown. The electron energy scales in Figs. 6,7 and 8 have been corrected by means of the method described above. Observed appearance potentials of both processes of the dissociative resonance capture and ion pair production are summarized in Table I. And also in Table I, the half widths of the dissociative resonance capture curves show for the relative sharpness of the resonance processes.

\section{3-3. Pressure Dependencies of Negative Ion Formations}

The typical semilogarithmic plots, which are plots of the logarithmic ion currents against the time duration of the pressure decrease as described previously, were shown in Fig. 9. In Fig. 9, typical types of the pressure dependencies of the negative ion formation were shown for simple, quadratic, cubic and biquadratic dependencies for the pressure. The plotted lines of the $\mathrm{M} / \mathrm{e}=26$ ions produced by the ionization voltages of 50 and $100 \mathrm{~V}$, have bended in mid region. These bended lines indicate that the lines having two or more different slope have been put upon together. The pressure dependencies of the negative ion formation by various electron energies were summarized in Table II for all observed ions. In Table II, the relative slope apart from integer that also to contain two or more processes as bended line. 
T. Sugiura, K. Arakawa and A. Matsumoto:

Vol. 14, No. 4, October 1966 Study of Negative Ion Formations by Electron Impact

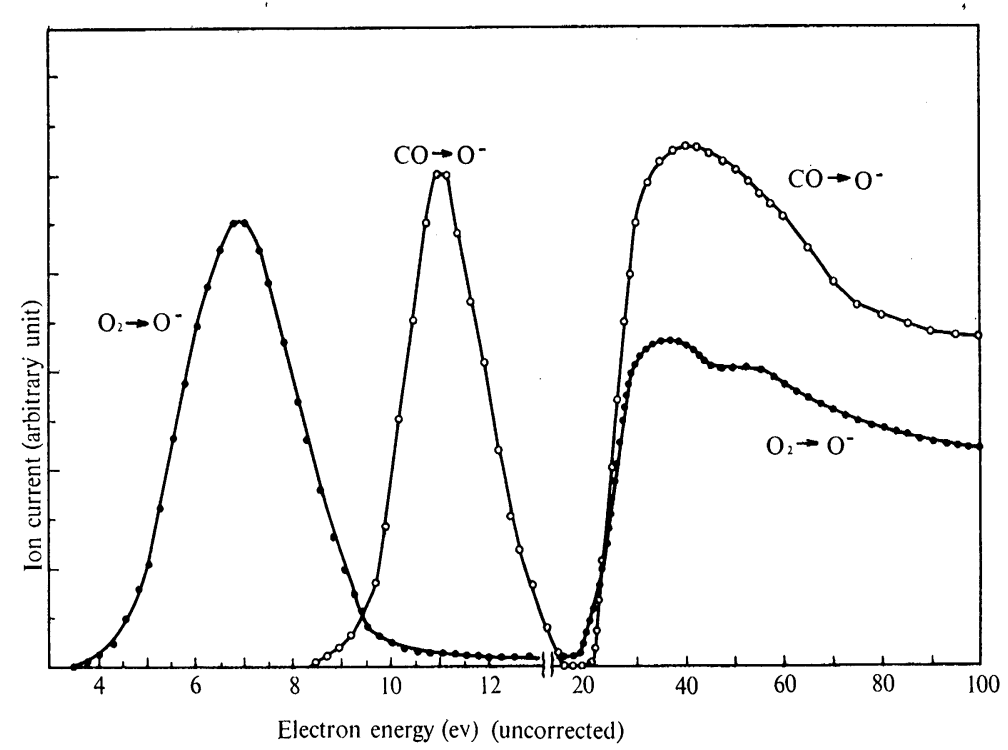

Fig. 5. The ionization efficiency curves for the formation of the $\mathrm{O}^{-}$ions from oxygen (- - $)$ and carbonmoxide (- - ) by electron impact.

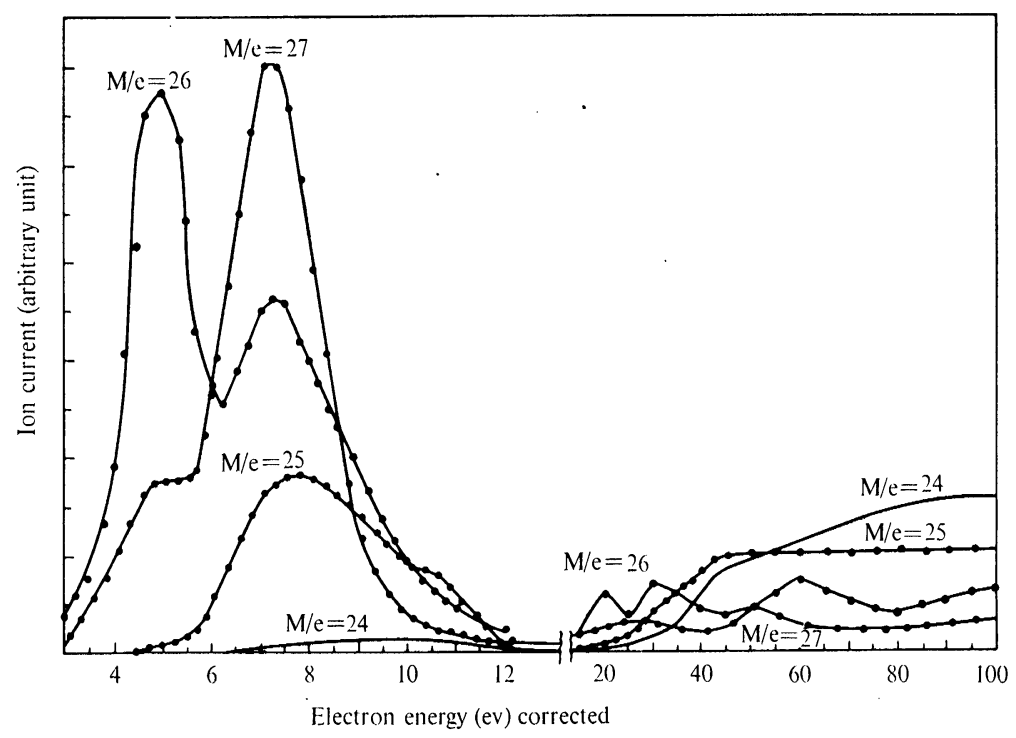

Fig. 6. The ionization efficiency curves for the formation of the $\mathrm{C}_{2}^{-}, \mathrm{C}_{2} \mathrm{H}^{-}, \mathrm{CN}^{-}$and $\mathrm{HCN}^{-}$ ions from acrylonitrile by electron impact.

\section{Discussion}

\section{4-1. Calibration Gases}

Generally, the negative ions are formed by the electron impact in two processes which are the resonance capture with or without the dissociation and the ion-pair production. The shape of the ionization efficiency curves in these cases has approximately delta function for the resonance capture and step function for the ion-pair production. As shown in Fig. 10, the shape of the resonance 


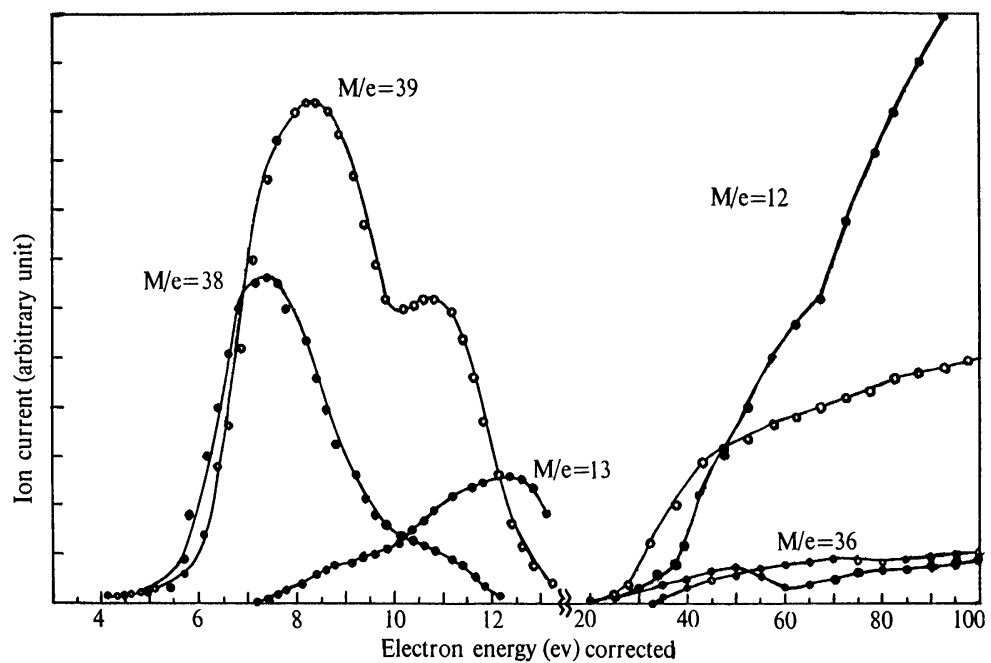

Fig. 7. The ionization efficiency curves for the formation of the $\mathrm{C}^{-}, \mathrm{CH}^{-}, \mathrm{C}_{3}^{-}, \mathrm{CCN}^{-}$and $\mathrm{CHCN}^{-}$ions from acrylonitrile by electron impact.

Table 1. Appearance potentials for negative ion formation from acrylonitrile by electron Impact

\begin{tabular}{|c|c|c|c|c|c|c|}
\hline \multirow{2}{*}{$\mathrm{M} / \mathrm{e}$} & \multirow{2}{*}{ Ion formular } & \multicolumn{4}{|c|}{ Dissociative Resonance Capture } & \multirow{2}{*}{$\begin{array}{c}\text { Ion Pair Production } \\
\text { A.P. (ev) }\end{array}$} \\
\hline & & $\begin{array}{c}\text { 1st A.P. } \\
\text { (ev) }\end{array}$ & $\begin{array}{l}\text { h.w. } \\
\text { (v) }\end{array}$ & $\begin{array}{c}\text { 2nd Ā.P. } \\
(\mathrm{ev})\end{array}$ & $\begin{array}{l}\text { h.w. } \\
\text { (v) }\end{array}$ & \\
\hline 52 & $\mathrm{CHCHCN}^{-}$ & $3.12 \pm 0.2$ & 1.35 & $4.53 \pm 1$ & 2.2 & $19.0 \pm 1$ \\
\hline 51 & $\mathrm{CCHCN}^{-}$ & $6.65 \pm 0.2$ & 1.85 & & & $19.5 \pm 1$ \\
\hline 50 & $\mathrm{C}_{2} \mathrm{CN}^{-}$ & $6.35 \pm 0.2$ & 2.5 & $8.85 \pm 1$ & 2.0 & $\begin{array}{l}28.8 \pm 1 \\
45.4 \pm 2\end{array}$ \\
\hline 39 & $\mathrm{CHCN}^{-}$ & $6.04 \pm 0.2$ & 3.4 & $9.50 \pm 1$ & 2.0 & $16.2 \pm 1$ \\
\hline 38 & $\mathrm{CCN}^{-}$ & $5.43 \pm 0.2$ & 2.2 & $7.85 \pm 1$ & 3.0 & $30.0 \pm 1$ \\
\hline 36 & $\mathrm{C}_{3}^{-}$ & & & & & $39.0 \pm 1$ \\
\hline 27 & $\mathrm{HCN}^{-}$ & $3.12 \pm 0.2$ & 1.5 & $4.77 \pm 0.5$ & 2.4 & $\begin{array}{l}28.0 \pm 1 \\
48.0 \pm 2\end{array}$ \\
\hline 26 & $\mathrm{CN}^{-}$ & $3.50 \pm 0.2$ & 1.5 & $5.87 \pm 0.5$ & 1.75 & $\begin{array}{l}14.5 \pm 1 \\
27.0 \pm 2 \\
44.5 \pm 2\end{array}$ \\
\hline 25 & $\mathrm{C}_{2} \mathrm{H}^{-}$ & $5.60 \pm 0.2$ & 3.1 & $8.70 \pm 0.5$ & 1.4 & $23.4 \pm 1$ \\
\hline 24 & $\mathrm{C}_{2}^{-}$ & $8.75 \pm 0.5$ & 3.5 & & & $\begin{array}{l}21.2 \pm 1 \\
34.7 \pm 2\end{array}$ \\
\hline 13 & $\mathrm{CH}^{-}$ & $7.47 \pm 0.5$ & 3.7 & & & $22.7 \pm 1$ \\
\hline 12 & $\mathrm{C}^{-}$ & & & & & $\begin{array}{l}21.7 \pm 1 \\
37.4 \pm 2 \\
69.2 \pm 3\end{array}$ \\
\hline
\end{tabular}

capture peak should be a reflection of the molecular ground state eigenfunction in the potential energy curve for the negative molecular ions. As illustrated in Fig. 10, this ionization efficiency curves of the resonance capture constructed so that it crosses the approximate boundaries of the FranckCondon region at point corresponding to the upper and lower threshold energies at which the negative 
T. Sugiura, K. Arakawa and A. Matsumoto:

Vol. 14, No. 4, October 1966 Study of Negative Ion Formations by Electron Impact

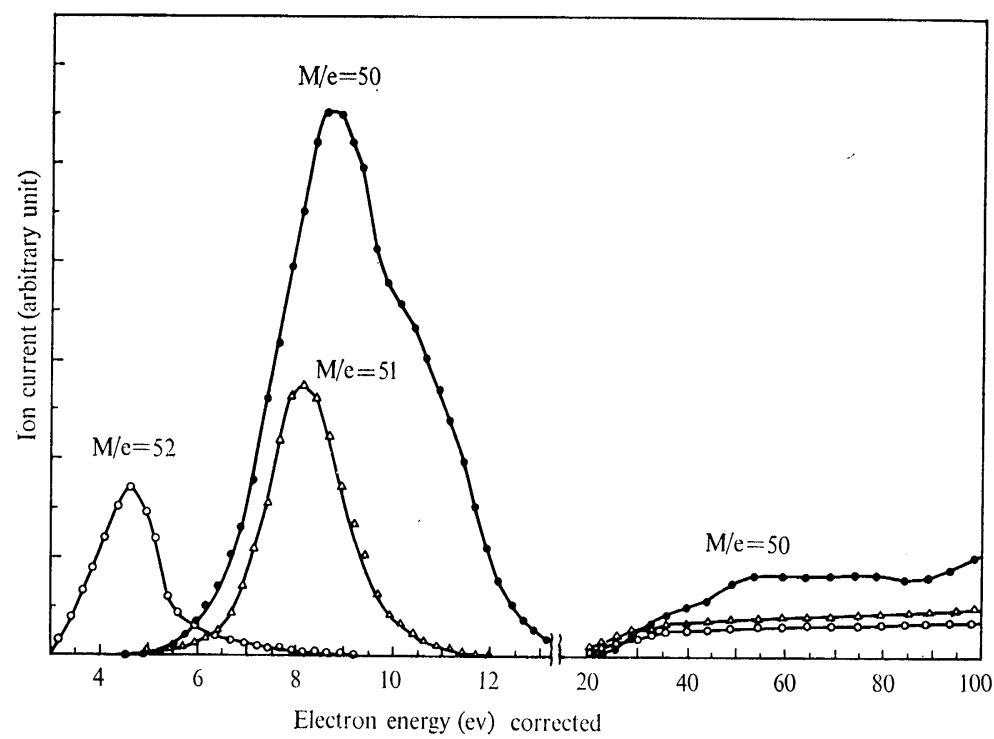

Fig. 8. The ionization efficiency curves for the formation of the $\mathrm{C}_{2} \mathrm{CN}^{-}, \mathrm{CCHCN}^{-}$and $\mathrm{CHCHCN}^{-}$ions from acrylonitrile by electron impact.

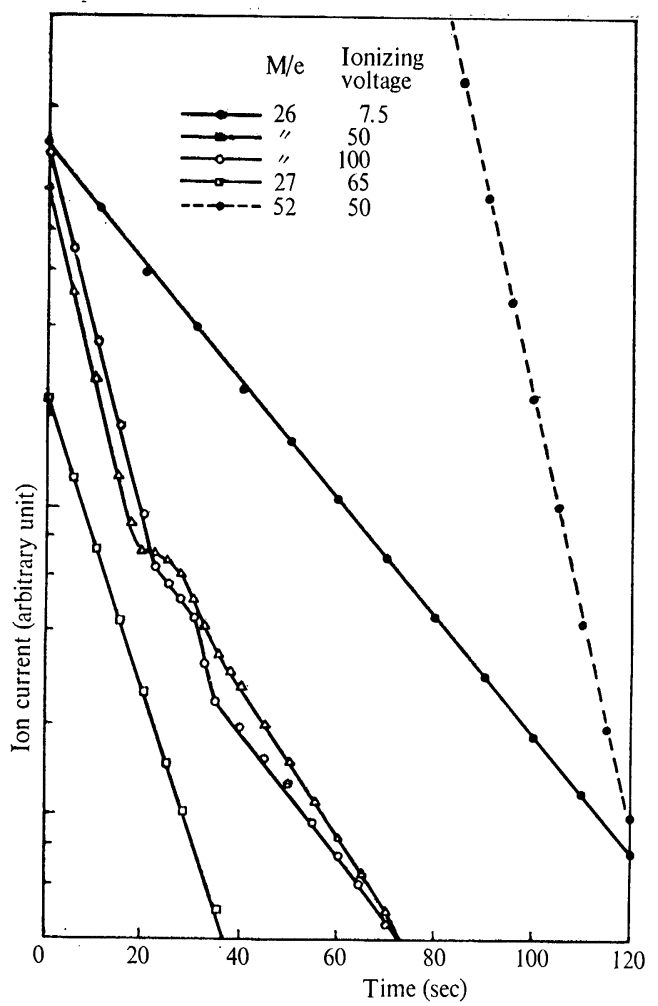

Fig. 9. The logarithmic ion currents as a function of the time duration for the pressure decrease. 
Table 2. Pressure dependencies of negative ion formations by various energies of electron

\begin{tabular}{|c|c|c|c|c|}
\hline $\mathrm{M} / \mathrm{e}$ & Ions & $\begin{array}{l}\text { Ionizing voltage } \\
\text { (v) }\end{array}$ & Relative slope & Pressure dependency \\
\hline 52 & $\mathrm{HCCHCN}^{-}$ & 4.5 & 1.09 & simple \\
\hline " & " & 7.0 & 1.83 & quadratic + simple \\
\hline " & $" \prime$ & 50,100 & 3.94 & biquadratic \\
\hline 51 & $\mathrm{CCHCN}^{-}$ & $7,10.5$ & 1.07 & simple \\
\hline$" 1$ & " & 50,100 & 4.06 & biquadratic \\
\hline 50 & $\mathrm{C}_{3} \mathrm{~N}^{-}$ & $11,12.5$ & 1.14 & simple \\
\hline$" \prime$ & " & 35,100 & 2.63 & cubic + quadratic \\
\hline " & $" \prime$ & 60 & 3.09 & cubic \\
\hline 39 & $\mathrm{HCCN}^{-}$ & 12 & 1.05 & simple \\
\hline " & " & $50,70,100$ & 1.96 & quadratic \\
\hline 38 & $\mathrm{CCN}^{-}$ & 7 & 0.8 & simple \\
\hline$" \prime$ & $" \prime$ & 100 & 2.18 & quadratic \\
\hline 36 & $\mathrm{C}_{3}^{-}$ & 50,60 & 2.18 & quadratic \\
\hline 27 & $\mathrm{HCN}^{-}$ & 11,25 & 1.03 & simple \\
\hline " & " & 65,100 & 2.03 & quadratic \\
\hline 26 & $\mathrm{CN}^{-}$ & $\begin{array}{lll}7.5, & 9.25, & 11\end{array}$ & 0.99 & simple \\
\hline$" 1$ & " & 50 & 3.01 and 1.50 & $\begin{array}{l}\text { cubic and } \\
\text { quadratic }+ \text { simple }\end{array}$ \\
\hline " & " & 100 & 3.01 and 1.05 & cubic and simple \\
\hline 25 & $\mathrm{C}_{2} \mathrm{H}^{-}$ & 11.75 & 1.00 & simple \\
\hline " & " & 100 & 2.19 & quadratic \\
\hline 24 & $\mathrm{C}_{2}^{-}$ & 60 & 2.1 & quadratic \\
\hline$" \prime$ & " & 100 & 1.74 & quadratic + simple \\
\hline 12 & $\mathrm{C}^{-}$ & 100 & 1.67 & quadratic + simple \\
\hline
\end{tabular}

ions observed. For these reason, the shapes of the ionization efficiency curves are important for understanding to the potential energy curves as well as the threshold energy. In consequence of the shape of the ionization efficiency curves of the ion-pair production processes, in spite of the use of the impacted electrons having wider energy spread, the higher appearance potentials could be easily identified than that of the single charged positive ions which have the simple linear function to the threshold law of the ionization efficiency curve. From the ionization efficiency curve of $\mathrm{O}^{-}$ ion formation from oxygen in Fig. 5, it is possible to observe the second threshold in the ion-pair production. The appearance potentials of the $\mathrm{O}^{-}$ions formed from oxygen and carbonmonoxide obtained in this work are shown in Table III., with comparison of other data of the literatures. The half widths of the resonance capture curves are also collected in Table III, by determining for the figures in the literatures. The obtained half width of this work is wider than that of the other investigaters, it is considered that the electron energy spread used this work is wider than the other, for reason of the higher electron currents $(100 \mu \mathrm{A})$ and higher sample pressure. The appearance potentials are not agreement in each literature, especially for the data of the oxygen. In spite of the disparity with the appearance potentials, the energy differencies between the threshold of the resonance capture and first onset of the ion pair production are almost agreement for each other. For this reason, it can be considered that the graduation of the electron energy scale of this work is practically linear at least from $3 \mathrm{ev}$ to $30 \mathrm{ev}$. 


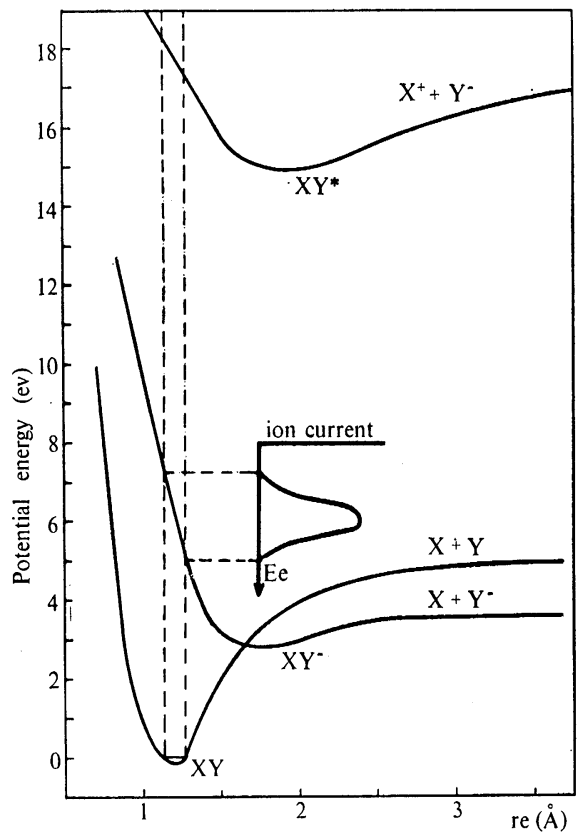

Fig. 10. Potential energy diagram to illustrate the formation of the $\mathrm{Y}^{-}$negative ions from diatomic molecule XY by the processes of the dissociative resonance capture (lower curve) and the ion pair production (upper curve). The scales of the potential energy and the inter-nuclear distance are an example for $\mathrm{O}^{-}$ion formation from oxygen, and then $\mathrm{X}, \mathrm{X}^{+}$and $\mathrm{Y}^{-}$are $\mathrm{O}\left({ }^{3} \mathrm{Pg}\right), \mathrm{O}^{+}\left({ }^{4} \mathrm{Su}\right)$ and $\mathrm{O}^{-}\left({ }^{2} \mathrm{Pu}\right)$, respectively.

Table 3. Comparison on appearance potentials of $\mathrm{O}^{-}$ions from $\mathrm{O}_{2}$ and $\mathrm{CO}$

\begin{tabular}{|c|c|c|c|c|}
\hline \multirow{2}{*}{\multicolumn{2}{|c|}{ Investigators }} & \multicolumn{2}{|c|}{ Dissociative resonance capture } & \multirow{3}{*}{$\begin{array}{l}\begin{array}{c}\text { Ion pair production } \\
\text { A.P. (ev) }\end{array} \\
17.6 \pm 0.2,22.3 \pm 0.3 \\
17.36,18.73,21.30 \\
19.5 \pm 0.2,21.8 \pm 0.2 \\
19.0,23.2\end{array}$} \\
\hline & & A.P. (ev) & Half width (v) & \\
\hline $\mathrm{O}_{2}$ & $\begin{array}{l}\text { This work } \\
\text { Frost et al. }{ }^{10} \\
\text { Omura et al. }{ }^{11} \\
\text { Hagstrum }^{12}\end{array}$ & $\begin{array}{l}4.53 * \\
4.53 \pm 0.03 \\
5.5 \pm 0.4 \\
6.3\end{array}$ & $\begin{array}{l}2.65 \\
1.80 \\
0.72 \\
2.30\end{array}$ & \\
\hline $\mathrm{CO}$ & $\begin{array}{l}\text { This work } \\
\text { Omura et al. }{ }^{11} \\
\text { Hagstrum }^{12}\end{array}$ & $\begin{array}{l}9.50 \pm 0.2 \\
9.3 \pm 0.2 \\
9.80\end{array}$ & $\begin{array}{l}1.75 \\
0.6 \\
1.0\end{array}$ & $\begin{array}{l}21.9 \pm 0.2 \\
21.3 \pm 0.2 \\
21.0\end{array}$ \\
\hline
\end{tabular}

* This value was used for the correction of electron energies.

\section{4-2. Variation of Negative Ion Current with Pressure}

From Table II, the pressure dependencies of the various negative ions from acrylonitrile may be summarized as follows:

(1) Exception of second resonance capture of $\mathrm{M} / \mathrm{e}=52$ ions, all of the ions produced by dissociative resonance capture vary linearly with pressure.

(2) The second resonance process of $\mathrm{M} / \mathrm{e}=52$ ions are included of quadratic and simple linear relations.

(3) The ion currents produced by the ion pair production, except the group of $\mathrm{C}_{2} \mathrm{CN}^{-}$and $\mathrm{CN}^{-}$ions, are proportional to the square of the pressure. 
(4) $M / e=26$ ions produced by the ion pair production have many complicated relation that include simple, quadratic and cubic relations.

(5) $\mathrm{M} / \mathrm{e}=50$ ions at $60 \mathrm{~V}$ have the relation of cubic, and that produced by 35 and $100 \mathrm{~V}$ ionizing voltages include the processes of quadratic and cubic relations to pressure.

(6) $\mathrm{M} / \mathrm{e}=51$ and 52 ions produced by electron impact over the energy of $50 \mathrm{~V}$ to $100 \mathrm{~V}$ have biquadratic relation to pressure.

Melton ${ }^{13}$ have classified on the pressure dependency of the formation of negative ions by electron bombardment under following:

Assume the over-all reaction involved in the production of $\mathrm{AB}^{-}$ion from $\mathrm{AB}$ by electron impact, by high-energy electrons given by

$$
\begin{array}{ll}
\mathrm{AB}+\mathrm{e}_{\mathrm{p}} & \longrightarrow \mathrm{AB}^{+}+\mathrm{e}_{\mathrm{s}}+\mathrm{e}_{\mathrm{p}}{ }^{\prime} \\
\mathrm{AB}+\mathrm{e}_{\mathrm{S}} & \longrightarrow \mathrm{AB}^{*-} \\
\mathrm{AB}^{*-}+\mathrm{AB} & \longrightarrow \mathrm{AB}^{-}+\mathrm{AB}
\end{array}
$$

where $e_{\mathrm{P}}, \mathrm{e}_{\mathrm{S}}$ and $\mathrm{e}_{\mathrm{P}}{ }^{\prime}$ are primary, secondary and degraded primary electrons, respectively. Holding $e_{p}$ constant, the pressure dependencies for the rates of formation of various species are simple, quadratic and cubic relations to the pressure for each of $\mathrm{e}_{\mathrm{s}}, \mathrm{AB}^{*-}$ and $\mathrm{AB}^{-}$, respectively. Then the intensity of $\mathrm{AB}^{-}$ions will approximately depend on cubic relation at low pressure, since reaction (c) is the rate determining step. At higher pressure, the intensity of $\mathrm{AB}^{-}$ions will have the quadratic relationship, because reaction (b) becomes the rate-determining step. For the case of low energy primary electron would eliminate reaction (a), the relation to the pressure of the formation of $\mathrm{AB}^{-}$ions is decrease one degree than the case of the high energy.

For the results of this work in Table II, the classification of Melton is not applicable as intact. For example, the relation between ion current and pressure of $M / e=12$ and 24 ions have the apart from integer over the wide pressure range, it is considered that they include the two processes which are simple and quadratic to pressure, and their ratio is constant over the range. Most of resonance capture curves observed in this work have the simple linear relation to pressure as seen in Table II, and it is shown that the mechanism of the ion formation by resonance transition is sponteneous process, as the following example of formation of $\mathrm{CN}^{-}$ions:

$$
\mathrm{CH}_{2} \mathrm{CHCN}+\mathrm{e}_{\mathrm{p}} \longrightarrow \mathrm{CH}_{2} \mathrm{CHCN}^{-*} \longrightarrow \mathrm{CN}^{-}+\mathrm{CH}_{2} \mathrm{CH}
$$

\section{4-3. Negative Ion Formation of Acrylonitrile}

For the identification of the species constructed ionization efficiency curves, the ionization efficiency curves of acrylonitrile-2- $d_{1}$ were also obtained, and they are illustrated on Figs. 11, 12 and 13. By comparison of the both ionization efficiency curves of the ions from $d_{1}$ and $d_{0}$ compound, and by the results of the pressure dependency in Table II, following conclusion may be derived.

The ionization efficiency curves of $\mathrm{M} / \mathrm{e}=24,25$ and 26 ions are not altered approximately between $d_{0}$ and $d_{1}$ compound, as seen in Figs. 6 and 11, and also $M / e=12$ and 13 ions have same results. For reason above, these ions are not included $\alpha$ hydrogn atoms.

The ionization efficiency curves of $M / e=27$ ions from $d_{1}$ compound are almost similar to the curve of $M / e=26$ curve, as seen in Fig. 11, and put the curves of $M / e=28$ upon the curve of $M / e=27$ in Fig. 11, it has obtained similar curve to $M / e=27$ curve in Fig. 6 . It is shown that the $M / e=27$ curves containe the rearrangement negative ions of $\beta-\mathrm{HCN}^{-}$and $\alpha-\mathrm{HCN}^{-}$ions, and these ions formed by resonance transition would be produced by simple sponteneous process like as reaction (3), and the precursor of the $\beta-\mathrm{HCN}^{-}$ions may have identical excited negative species with that of $\mathrm{CN}^{-}$ion formed by resonance process. 
T. Sugiura, K. Arakawa and A. Matsumoto:

Vol. 14, No. 4, October 1966 Study of Negative Ion Formations by Electron Impact

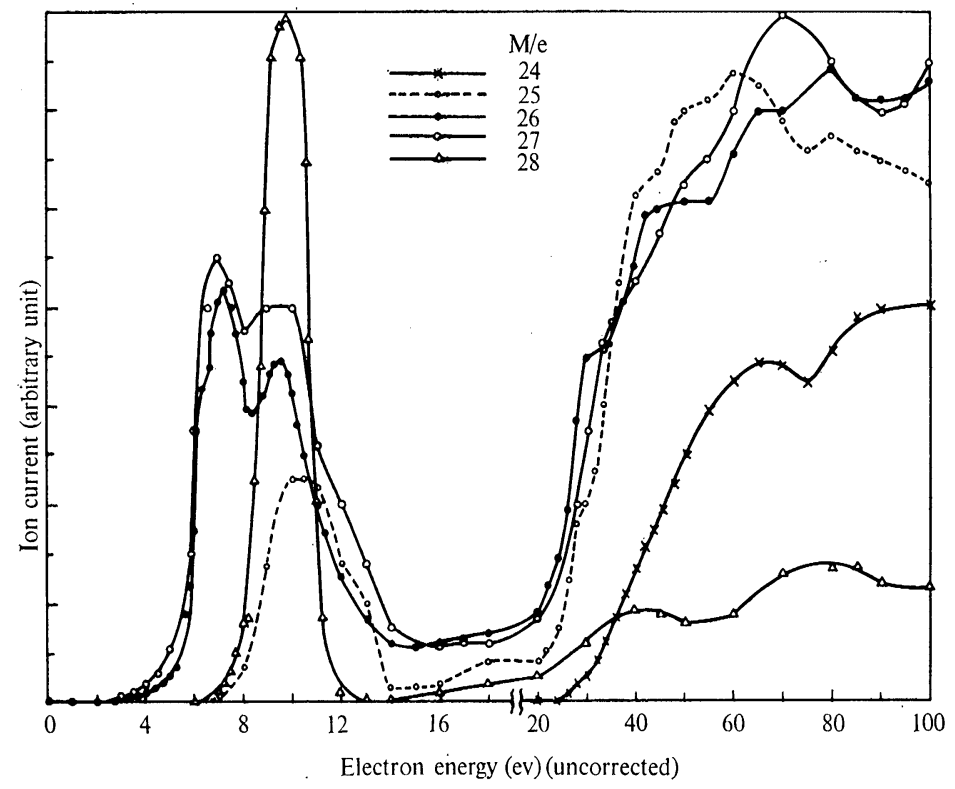

Fig. 11. The ionization efficiency curves for the formation of the $\mathrm{C}_{2}^{-}, \mathrm{C}_{2} \mathrm{H}^{-}, \mathrm{CN}^{-}, \mathrm{HCN}^{-}$ and $\mathrm{DCN}^{-}$ions from acrylonitrile-2- $\mathrm{d}_{1}$ by electron impact.

By the low energy electron bombardment, $M / e=25,26,27,38$, and 39 ions are presumably produced by sponteneous dissociation from each excited negative species formed by resonance transition (reaction (3)), because of the results of pressure dependency. In the other side by the high energy electron bombardment, with the exception of $\mathrm{CN}^{-}$ions, all of these ions would produce with counterpart positive ions from excited molecule by collisional deactivation in bimolecular with other molecules as following equations:

$$
\begin{aligned}
& \mathrm{XY}+\mathrm{e}_{\mathrm{P}} \longrightarrow \mathrm{XY}^{*}+\mathrm{e}_{\mathrm{p}}{ }^{\prime} \\
& \mathrm{XY}^{*}+\mathrm{XY} \longrightarrow \mathrm{X}^{+}+\mathrm{Y}^{-}
\end{aligned}
$$

$\mathrm{CN}^{-}$ions formed by higher electron energies would contain more complex processes.

As seen Fig. 8 and 12, the ionization efficiency curves of $\mathrm{M} / \mathrm{e}=50$ ions are identical shapes in both of $d_{0}$ and $d_{1}$-compounds, and also the ionization efficiency curves of $M / e=52$ (in Fig. 8) and $\mathrm{M} / \mathrm{e}=53$ (in Fig. 12) are identical, but the $\mathrm{M} / \mathrm{e}=51$ curve (in Fig. 8) is identical shape only to second resonance curve of $\mathrm{M} / \mathrm{e}=52$. The first curve of resonance transition of $\mathrm{M} / \mathrm{e}=52$ ions have similarity rather to the curves of $\mathrm{M} / \mathrm{e}=53$ (in Fig. 12) or $\mathrm{M} / \mathrm{e}=52$ (in Fig. 8). Accordingly to this, a part of $\mathrm{M} / \mathrm{e}=52$ ions of $\mathrm{d}_{0}$-compound are necessary consist of $\alpha, \beta-\mathrm{CH}_{2} \mathrm{CCN}^{-}$ions. From the dependency of the ion current to pressure, as a part of the mechanism of the second resonance transition formed $\mathrm{M} / \mathrm{e}=\mathbf{5 2}$ ions, the following process may be considered:

$$
\begin{aligned}
& \mathrm{CH}_{2} \mathrm{CHCN}+\mathrm{e}_{\mathrm{P}} \longrightarrow \mathrm{H}^{-}+\mathrm{C}_{2} \mathrm{H}_{2} \mathrm{CN} \\
& \mathrm{CH}_{2} \mathrm{CHCN}+\mathrm{H}^{-} \longrightarrow \mathrm{CHCHCN}^{-}+\mathrm{H}_{2}
\end{aligned}
$$

By high energy electrons, $M / e=51$ and 52 ions produced have the biquadratic relation to the pressure, it is difficult to consider the mechanisms of these ion formations.

The authors have found that some of the negative ion currents acutely depend on the ion accelerating potentials, it is considered to suggest that some of the negative ions have the shorter life time than the positive ions. It is necessary to continue the studies of the acceleration dependency 


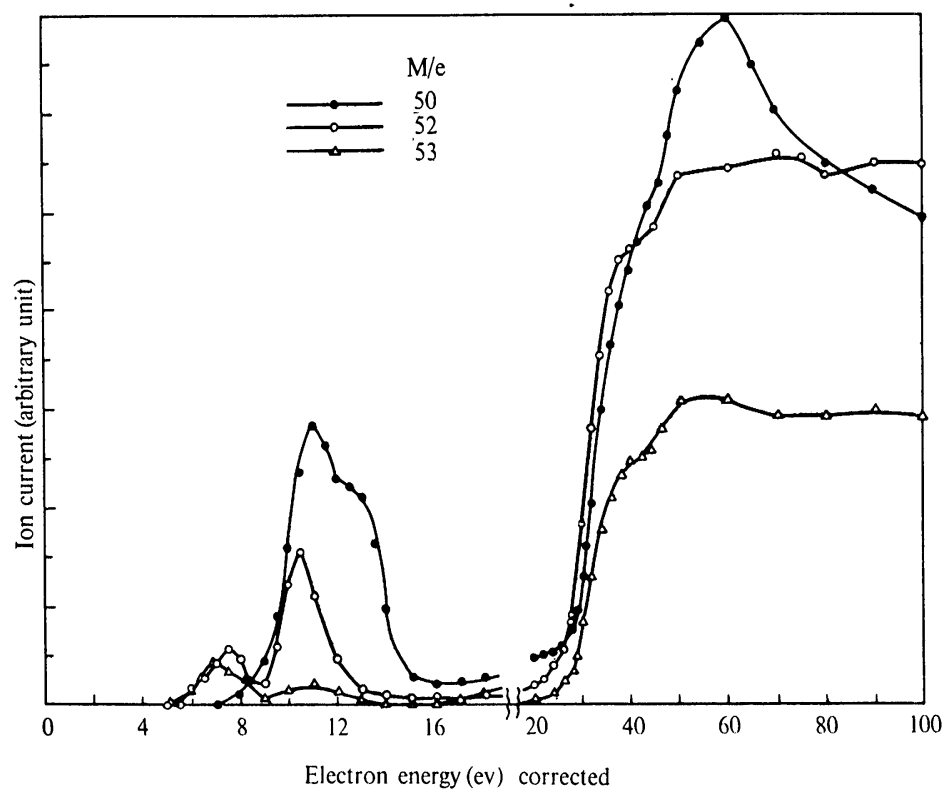

Fig. 12. The ionization efficiency curves for the formation of the $\mathrm{C}_{2} \mathrm{CN}^{-}, \mathrm{C}_{2} \mathrm{DCN}^{-}$and $\mathrm{HCCDCN}^{-}$ions from acrylonitrile-2- $\mathrm{d}_{1}$ by eletron impact.

of the negative ion currents and of the $\mathrm{H}^{-}$ion formation.

The authors wish to acknowledge their indebtedness to Professor Shyoji Shida of the Tokyo Institute of Technology, and to Professor Teruo Hayakawa of the University of Osaka Prefecture, under whose direction and guidance this work was carried out.

\section{References}

1) R.T. Aplin, H. Budzikiewiez and C. Djerassi, J. Am. Chem. Soc., 87, 3180 (1965).

2) M.v. Ardenne, R. Tümmler, Ek. Weiss und T. Reichstein, Helv. Chem. Actq., 47, 1032 (1964).

3) K. Mothes, H.R. Schütte, P. Müller, M.v. Ardenne und R. Tümmler, z. Naturforshg., 19B, 1161 (1964).

4) W.M. Hickam and D. Berg, J. Chem. Phys., 29, 517 (1958).

5) D.C. Frost and C.A. McDowell, Can. J. Chem., 38, 407 (1960).

6) W.H. Hickam and R.E. Fox, J. Chem. Phys., 25, 642 (1956).

7) E.E. Muschlitz, J. Appl. Phys., 28, 1414 (1957).

8) A. Henglein and G.A. Muccini, J. Chem. Phys., 31, 1426 (1959).

9) C.E. Melton, G.A. Ropp and T.W. Martin, J. Phys. Chem., 64, 1577 (1960).

10) D.C. Frost and C.A. McDowell, J. Am. Chem. Soc., 80, 6183 (1958).

11) I. Omura and N. Morito, Mass Spectrometry, 10, 29 (1962). (in Japanese)

12) H.D. Hagstrum, Rev. Mordern Phys. 23, 185 (1951).

13) C.E. Melton in "Mass Spectrometry of Organic Ions" F.W. McLafferty, Ed., Academic Press Inc., New York, 1963, Chapter 4. 